ORIGINAL ARTICLE

\title{
Cross-cultural Adaptation and Validation of Hindi Version of Child Oral Impacts on Daily Performance Index
}

\author{
Puneet Chahar ${ }^{1}$, Vikrant Mohanty ${ }^{2}$, Aswini Y Balappanavar ${ }^{3}$, Vipul Yadav $^{4}$, Shivam Kapoor ${ }^{5}$
}

\begin{abstract}
Introduction: Oral diseases may have an impact on quality of life (QoL) and the oral health-related quality of life (OHRQoL). As compared to clinical measures which are unable to provide a complete picture, OHRQoL indices quantify the oral health impact on overall health. Worldwide indices have been developed to measure the OHRQoL in children but none can be applicable in Indian context.

Aim: The aim of the study was cross-cultural adaptation and psychometric analysis of Hindi version of child oral impacts on daily performance (C-OIDP) index.

Materials and methods: Translation and back translation were done for index using prescribed guidelines for cross-cultural adaptation. A pilot study was conducted in 32 children and required modifications were done. The final Hindi version was tested for reliability and validity on a convenience sample of 64 children aged 11-14 years selected from public schools in Delhi. The psychometric properties of the Hindi version were tested for face, content, construct validity along with internal consistency, and test-retest reliability.

Results: The mean age of the final sample $(n=64)$ was $13.02 \pm 0.93$ years with boys $(51.6 \%)$ and girls $(48.4 \%)$. The mean C-OIDP score was $8.8 \pm 7.8$. Significant association was obtained when C-OIDP was compared with self-perceived oral health. Interitem correlation ranged from -0.008 to 0.45. Kappa for categories of child OIDP ranged from 0.711 to 1.00 and intraclass correlation coefficient was 0.91 .

Conclusion: The Hindi version of C-OIDP is a valid and reliable tool to measure OHRQoL in Hindi-speaking children in India.

Keywords: Child OIDP, Oral health, Oral health-related quality of life, Psychometric analysis, Sociodental indicator.

International Journal of Clinical Pediatric Dentistry (2020): 10.5005/jp-journals-10005-1720
\end{abstract}

\section{INTRODUCTION}

Health as a multidimensional phenomenon led to change in concepts of health with the development of various sociomedical indicators to assess it. ${ }^{1-3}$ With regard to field of dentistry, it was Cohen and Jago in 1976 and later Locker and Grushka who recommended the development of "sociodental indicators" to assess oral health-related quality of life (OHRQoL). ${ }^{4-6}$

Oral health-related quality of life $(\mathrm{QoL})$ is "a multidimensional construct that reflects (among other things) people's comfort when eating, sleeping, and engaging in social interaction; their selfesteem; and their satisfaction with respect to their oral health." ${ }^{7,8}$ Oral health-related QoL measures are relatively common in adults, but it is relatively less explored in children. Children are affected by numerous orofacial disorders which may affect child's selfesteem and confidence, thus ultimately affecting the OHRQoL.9,10 Various tools have been developed but child oral impacts on daily performance (C-OIDP) is very popular measure for the assessment of OHRQoL in children, which was originally developed in Thailand. ${ }^{11-15}$ It is short, comprehensive, and successfully translated and tested in various other settings, such as France, Brazil, United Kingdom, Malaysia, and Chili. ${ }^{2,16-19}$ In India, it has been validated in Kannada, but it is not feasible and practical to use this version of C-OIDP in every part of the country. ${ }^{20,21}$ India is one of the multilingual countries in the world, and Hindi is the most widely spoken official language in Northern parts of India with $45 \%$ using it in regular communications. $^{22}$

Development of a new instrument in pediatric population to measure QoL comes with a lot of methodological and conceptual problems. ${ }^{23,24}$ Therefore, using a translated version of the existing OHRQoL measure is acceptable. ${ }^{25}$ There is no universal agreement on how to adapt an instrument for use in another cultural setting.
${ }^{1-5}$ Department of Public Health Dentistry, Maulana Azad Institute of Dental Sciences, New Delhi, India

Corresponding Author: Puneet Chahar, Department of Public health Dentistry, Maulana Azad Institute of Dental Sciences, New Delhi, India, Phone: +91 9891618522, e-mail: Puneetchahar@rocketmail.com

How to cite this article: Chahar P, Mohanty V, Balappanavar AY, et al. Cross-cultural Adaptation and Validation of Hindi Version of Child Oral Impacts on Daily Performance Index. Int J Clin Pediatr Dent 2020;13(2):124-129.

Source of support: Nil

Conflict of interest: None

However, there is agreement that it is inappropriate to simply translate and use a questionnaire in another linguistic context; therefore, a stepwise approach has to be adapted to maintain validity of the measure at a conceptual level across multiple cultures. ${ }^{26,27}$

The high risk and prevalence of oral diseases among children in India require an $\mathrm{OHRQ}$ oL measure, which can sensitize policymakers in assessing need, prioritizing care, and evaluating treatment outcomes. ${ }^{28,29}$ Therefore, the aim of the study was cross-cultural adaptation and psychometric analysis of Hindi version of the C-OIDP index.

\section{Materials and Methods}

This cross-sectional study for cross-cultural adaptation of an OHRQoL tool in Hindi for children was conducted on 96 children. Data collection was carried out from 15 August to 15 October, 2016 on 11-14-year-old school children of public schools in North East 
district, Delhi. Data collection was carried out from 15 August to 15 October on 11-14-year-old school children of public schools in North East district, Delhi. The necessary permissions were obtained from the Directorate of Education, Delhi, to conduct study within the school premises. The parents and guardians were informed about the study objectives, and an informed consent was obtained at parents-teacher meeting. Furthermore, permission was obtained from the School Principal to conduct the study after explaining the research objectives. Ethical clearance for the study was obtained from the Institutional Ethical Review Board.

\section{Tool Used}

The C-OIDP is an interviewer-administered OHRQoL indicator. Children are first given a list of common oral problems and are asked whether they have experienced them within the last 3 months. This is followed by an interview which investigates any difficulty in daily life caused by the problems that they have marked on the list. The impacts of oral problems on daily life are quantified by using frequency and severity scores for difficulty in carrying out eight performances (eating, speaking, cleaning mouth, sleeping, emotion, smiling, study, and social contact). In the event that a child reports an impact on their performance, the child responds to questions (both severity and frequency) of the specific impact, and thus a score from zero to three is given to rate each of these characteristics. When no impact is reported, the child receives a score of zero. The calculation of the index involves the multiplication of the severity and frequency of each performance. A sum is made of the values obtained for the eight performances, resulting in a number from 0 to 72 , which is divided by 72 and then multiplied by 100 , so that the final C-OIDP score varies from 0 to 100. A more detailed description of the index can be obtained in the development paper of the C-OIDP. ${ }^{13}$

\section{Cross-cultural Adaptation}

The development of the Hindi C-OIDP index required a cultural adaptation and psychometric analysis of the English C-OIDP index into its Hindi version and followed proposed guidelines. ${ }^{26}$ This was achieved in two phases: (1) linguistic and (2) psychometric validation of Hindi version of C-OIDP. The permission to adapt the C-OIDP index was obtained from the author. Forward translation of English version was done by two translators (one informed and one uninformed). A common translated version was obtained after combining two translated versions. The next step of validity checking was back translation of common translated Hindi version, which made sure that it was reflecting the same item content as the original versions. The forward and back translations were carried out by linguistic experts in Hindi and English, whereas modified by the dental professional expert's team to suit its use in clinical applications. The back-translated version of the index was sent for verification by the original authors of the C-OIDP index. The training and calibration of the investigator were done for interview and clinical examination during this period.

\section{Face-Content Validity}

The expert committee after receiving inputs from the original author and in the presence of all the versions of the index reached a consensus on discrepancies. The expert committee achieved equivalence (in terms of Semantic, Experiential, and Conceptual equivalence) between source and target version, and thus a prefinal version of Hindi C-OIDP was obtained. The prefinal Hindi version so obtained was tested on a sample group of 32 children from the similar setting. Following the test, each student was interviewed to probe about what he or she thought was meant by each item and the chosen response. This confirmed the feasibility and suitability of tool used for the study with only minor modification of wording of the questionnaire. The minor modification was related to the slang of Indian English used in children. These subjects were not included in the main study.

\section{Reliability and Validity}

The final version so obtained was tested again in a convenience sample of 64 children from two public schools of North East Delhi for psychometric analysis. The sample included 11-14-year-old school children (both boys and girls) randomly selected from sixth standard to eighth standard. For the application of the C-OIDP, the children were initially asked to record all oral health-related problems they have experienced in the past 3 months. This was done in small groups to reduce time. Then, data were collected on the impacts of oral problems, through face-to-face interviews, considering eight common daily performances. Along with this the sociodemographic data perceived oral health status, dental visit in the past 12 months, and past dental experience were recorded. The clinical variables, such as caries experience, gingival status, dental trauma, and enamel fluorosis, were assessed using the WHO 2013 oral health assessment questionnaire and form. ${ }^{30}$ For test-retest reliability, 26 students were again interviewed after 1 week.

\section{Data Analysis}

Data were entered into MS Excel spreadsheet and analyzed using SPSS (version 17.0; SPSS Inc., Chicago, IL, USA). In this study, the psychometric analysis of the Hindi version of the C-OIDP index involved the assessment of internal and test-retest reliability, as well as face, content, and construct validity. Internal reliability was tested by using the standardized Cronbach's alpha coefficient, as well as item-total and interitem correlations. Test-retest reliability was tested by using the intraclass correlation coefficient (ICC) using the two-way random-effects model for the C-OIDP score. The reliability tests were carried out to ensure that the C-OIDP index would be interpreted consistently at different times. Face and content validity were established during the linguistic validation in the first phase by expert panel. Construct validity was tested by comparing its relationships with other measures measuring related constructs, that is, perceived oral health status and toothache experience in the previous 12 months. Significance value was fixed at $p<0.05$. Normal distribution was checked by the Shapiro-Wilk test. Parametric (independent $t$ test) and nonparametric statistical tests (Kruskal-Wallis and Mann-Whitney test) were used to assess relationships between C-OIDP and subjective/normative measures.

\section{Results}

A total of 64 students underwent the study, and mean age of the sample was $13.02 \pm 0.93$ years (median $=13$ ). Sample constituted almost equal number of males (51.6\%) and females (48.4\%). Around $84 \%$ of the students were from nuclear family and rest reported to have a joint family. Mean number of siblings was $2.5 \pm 1.2$. The self-perceived oral health as reported by the students was good (32.8\%), average (37.5\%), and poor (29.7\%).

Table 1 represents distribution of oral problems as reported by the children. The most common oral problems related to oral impacts in descending order were color, sensitivity, oral ulcer, and toothache. Shape or size of tooth, erupting permanent tooth, and missing permanent tooth were least reported oral problems. 
The distribution of impact on daily performances because of reported oral health problems is presented in Table 2. Overall, $93.75 \%$ of the sample reported at least one oral impact in the last 3 months. The most prevalent impact was difficulty in eating (75\%) followed by difficulty in cleaning mouth (39.1\%) and smiling and laughing (37.5\%). The least prevalent impacts were relaxing (9.4\%), contact with people (7.8\%), and speaking clearly (3.1\%). The mean

Table 1: Distribution of oral problems in the sample

\begin{tabular}{lll}
\hline Impact & Percentage & $n$ \\
\hline Color of tooth & 60.9 & 39 \\
Sensitive tooth & 51.6 & 33 \\
Oral ulcers & 48.4 & 31 \\
Toothache & 32.8 & 21 \\
Bleeding gum & 29.7 & 19 \\
Tooth space (due to a nonerupted & 28.1 & 18 \\
permanent tooth) & & \\
Position of tooth & 25.0 & 16 \\
Swollen gum & 25.0 & 16 \\
Bad breath & 20.9 & 13 \\
Exfoliating primary tooth & 12.5 & 8 \\
Calculus & 12.5 & 8 \\
Tooth decay, hole in tooth & 10.9 & 7 \\
Fractured permanent tooth & 10.9 & 7 \\
Shape or size of tooth & 9.4 & 6 \\
Erupting permanent tooth & 6.3 & 4 \\
Missing permanent tooth & 1.6 & 1 \\
Deformity of mouth or face & 0.00 & 0 \\
\hline
\end{tabular}

Table 2: Distribution and mean child oral impact on daily performances

\begin{tabular}{lcc}
\hline Daily performance & Percentage & $\begin{array}{c}\text { Mean score } \\
\text { for each item }\end{array}$ \\
\hline Eating & 75.0 & $2.14 \pm 2.3$ \\
Speaking clearly & 3.1 & $0.007+0.4$ \\
Cleaning your mouth & 39.1 & $0.89+1.5$ \\
Sleeping & 9.4 & $0.34+1.4$ \\
Maintaining your usual emotional & 31.3 & $0.89+1.7$ \\
state without being irritable & & \\
Smiling, laughing, and showing your & 37.5 & $1.51+2.5$ \\
teeth without embarrassment & & \\
Carrying out your schoolwork & 20.3 & $0.32+0.8$ \\
Contact with people & 7.8 & $0.2+0.7$ \\
\hline
\end{tabular}

C-OIDP score for the sample was $8.87 \pm 7.8$. The mean C-OIDP was higher for males $(11.32 \pm 8.03)$ when compared with females $(6.27 \pm 6.85)$ which when compared was found to be statistically significant ( $z=-3.02, p=0.003$, significant). The mean C-OIDP score for individual daily performances affected was highest for eating $(2.14 \pm 2.3)$, followed by smiling, laughing, and showing teeth without embarrassment.

In terms of internal reliability, the interitem correlation coefficients among eight items ranged from -0.008 between school work and eating/emotions and social contact to 0.45 . A vast majority of interitem correlations were positive but few were negative. The corrected item-total correlation coefficients ranged from 0.08 (doing homework, social contact) to 0.43 (sleeping). The standardized Cronbach's alpha coefficient was 0.46 . Furthermore, the alpha coefficient did not increase when any of the items were deleted (Tables 3 and 4).

Test-retest reliability is the degree of agreement between two measurements taken at two different points in time using the same scale and with the same respondents; this provides an estimation of the degree to which the results are reproducible. ${ }^{14}$ In this study, Kappa for categories of C-OIDP ranged from 0.711 to 1.00 , and the intraclass correlation was 0.91 which showed excellent agreement.

The relationship between the child-OIDP score and the selfrated oral health measures demonstrated that children with perceptions of poor oral health had a higher score of the index than children who reported their oral health as good. Children who reported toothache and discomfort in mouth "Often" had significantly higher score when compared with those who reported "Never" or "Occasionally/Rarely" (Table 5).

Results also showed that C-OIDP was able to discriminate between normative dental situations, although the differences could not reach significance. Children with at least one carious tooth [decayed, filled teeth score $(\mathrm{dft})>0$, Decayed Missing Filled Teeth score (DMFT) $>0$ ] in either permanent or mixed dentition reported higher C-OIDP scores $(16.6 \pm 11.6$ in group with $\mathrm{dft}>0$ and $9.4 \pm 9.0$ in DMFT >0) when compared with those who were caries free. Similar pattern was observed in other clinical variables, with higher C-OIDP in those having the gingival bleeding and dental fluorosis (Table 6).

\section{Discussion}

Assessment of individual patient needs requires much broader concepts based on perceived need and impacts, thus this study contributes to a pioneer effort to cross culturally adapt the C-OIDP index in Hindi and test its psychometric properties. ${ }^{31}$

Table 3: Interitem correlation

\begin{tabular}{|c|c|c|c|c|c|c|c|c|}
\hline Performances & Eating & Speaking & Cleaning & Sleeping & Emotions & Smiling & School work & $\begin{array}{l}\text { Contact } \\
\text { with people }\end{array}$ \\
\hline Eating & 1 & & & & & & & \\
\hline Speaking & -0.087 & 1 & & & & & & \\
\hline Cleaning & 0.130 & -0.104 & 1 & & & & & \\
\hline Sleeping & 0.170 & -0.043 & 0.099 & 1 & & & & \\
\hline Emotions & -0.111 & 0.090 & -0.057 & 0.129 & 1 & & & \\
\hline Smiling & 0.128 & $0.328^{*}$ & 0.122 & $0.369 * *$ & -0.008 & 1 & & \\
\hline School work & -0.008 & 0.068 & -0.069 & $0.446^{* *}$ & $0.490^{* *}$ & 0.023 & 1 & \\
\hline Contact with people & 0.002 & 0.050 & 0.035 & 0.071 & $0.277^{*}$ & -0.024 & $0.459 * *$ & 1 \\
\hline
\end{tabular}

*Significant at $5 \%$ level, ${ }^{* *}$ significant at $1 \%$ level 
Table 4: Corrected item total correlation and Cronbach's alpha if item deleted

\begin{tabular}{lll}
\hline Daily performances & $\begin{array}{l}\text { Corrected item } \\
\text { total correlation }\end{array}$ & $\begin{array}{l}\text { Cronbach's alpha } \\
\text { if item deleted }\end{array}$ \\
\hline Eating & 0.10 & 0.42 \\
Speaking & 0.08 & 0.40 \\
Cleaning & 0.10 & 0.39 \\
Sleeping & 0.43 & 0.25 \\
Emotions & 0.09 & 0.40 \\
Smiling and laughing & 0.25 & 0.31 \\
School work & 0.32 & 0.33 \\
Contact with people & 0.17 & 0.38 \\
Alpha value & & 0.39 \\
Standardized items alpha & & 0.46 \\
\hline
\end{tabular}

Table 5: Construct validity: child OIDP and self-reported measures of oral health $(n=64)$

\begin{tabular}{lccc}
\hline Variables & $n$ & Child OIDP quartiles & p value \\
\hline Self-perceived oral health & & & \\
$\quad$ Good & 21 & $(1.3,2.7,7.6)$ & $0.04^{\mathrm{a}}, \mathrm{S}$ \\
Average & 24 & $(3.1,7.1,10.6)$ & \\
Poor & 19 & $(5.5,11.1,18.5)$ & \\
Toothache or discomfort in mouth in the last 3 months & \\
Never & 20 & $(2.7,7.6,10.4)$ & $0.008^{\mathrm{a}}, \mathrm{S}$ \\
Occasionally or rarely & 35 & $(2.7,5.5,11.1)$ & \\
Often & 9 & $(8.3,12.5,20.8)$ & \\
\hline
\end{tabular}

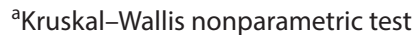

$\mathrm{S}$, significant; NS, nonsignificant; OIDP, oral impacts on daily performance

Table 6: Relationship between child OIDP and clinical dental status

\begin{tabular}{lrcc}
\hline Variables & $n$ & Child OIDP mean & pvalue \\
\hline $\begin{array}{l}\text { Temporary teeth } \\
\text { dft }=0\end{array}$ & 19 & $9.5 \pm 9.6$ & $0.57^{\mathrm{a}}, \mathrm{NS}$ \\
$\quad \mathrm{dft}>0$ & 5 & $16.6 \pm 11.6$ & \\
$\begin{array}{l}\text { Permanent teeth } \\
\text { DMFT }=0\end{array}$ & 35 & $8.3 \pm 6.7$ & $0.17^{\mathrm{b}}, \mathrm{NS}$ \\
$\quad$ DMFT $>0$ & 29 & $9.4+9.0$ & \\
Gingival bleeding & & & \\
$\quad$ No & 15 & $6.5 \pm 5.2$ & $0.26^{\mathrm{b}}, \mathrm{NS}$ \\
$\quad$ Yes & 49 & $9.5 \pm 8.4$ & \\
Enamel fluorosis & & & \\
$\quad$ No & 44 & $8.4 \pm 8.0$ & $0.36^{\mathrm{b}}, \mathrm{NS}$ \\
$\quad$ Yes & 20 & $9.8 \pm 7.4$ & \\
\hline
\end{tabular}

andependent sample $t$ test; ${ }^{\mathrm{b}}$ Mann-Whitney $U$ test

$S$, significant; NS, nonsignificant; OIDP, oral impacts on daily performance

The results in this study were promising, showing satisfactory reliability and validity. The cross-cultural adaptation followed the recommended guidelines by Beaton et al., ${ }^{26}$ and the back-translated version was very similar to the original, thus highlighting the appropriateness of the Hindi version. Face and content validity were assessed during the pilot study, which introduced minor wording modification in the index. Again, such changes highlight challenges involved when applying an index in a different cultural context and English dialect.
Internal consistency of the index, which was measured by Cronbach's alpha, was found to be satisfactory (0.46) and comparable to other results obtained while validating the index in other cultural settings, ${ }^{3,16,20}$ but it was lower than those found in Uganda, Malaysia, and Chili. ${ }^{15,18,19}$ The alpha value did not increase when any of the item was deleted. It is evident that QoL is a multidimensional concept, and therefore any tool will have various dimensions. Moreover, the alpha value depends on the correlation between the items and the number of items in the scale, with scales having a fewer items revealing a low alpha value. ${ }^{32}$ Although the alpha can be increased by increasing the number of items, it would be difficult to justify because OHRQoL measures should be brief as possible and user-friendly, cost-effective, and yet capture all dimensions related to OHRQoL. Also, criterion for adequate validity depends on the purpose of measure. For group comparison, reliability does not have to be as high as it would have to be for the purpose of individual comparison. ${ }^{32-34}$ Lower alpha value can be considered an inherent attribute to an index designed to be brief and practical for assessing needs in a population. The alpha in this study was therefore considered satisfactory.

Internal consistencies measured via interitem correlation generated satisfactory results with few negative correlations. Most of the negative correlations were nearly 0 , but observation of 0 correlation should never be the criteria to remove the items as they may be rather more prevalent in a larger sample study, thus generating a positive correlation. ${ }^{35}$ Negative correlations were mainly observed when items were correlated with speaking, emotions, or social contact. Prevalence of speaking and social contact was very low in this study, which might have generated such observations with other items. Such negative correlation may have also contributed to lower alpha value in this study. Also, a differential background and cultural understanding may explain the differences observed. Also, it may be due to the child perceptions being variant with emotions and time along with a lower sample size.

The reproducibility of the tool was assessed by the test-retest procedure, and ICC (0.91) indicated an excellent agreement. This was better than other studies in different settings.,.$^{3,17-19}$ The opinion of target population in pilot testing would have contributed to this result. Assessing the $\mathrm{OHRQ}$ L is a complex phenomenon in younger children. A varied understanding of health which is chiefly determined by their cognitive and emotional development can influence the overall reliability of the index. ${ }^{36}$ The kappa value for test-retest reliability was also satisfactory which further substantiated the reproducibility of the index.

The construct validity of the index was also evaluated, and it was observed that scores increased progressively, indicating poor OHRQoL, as the self-perceived oral health changed from good to poor and toothache or discomfort in the past 3 months changed from never to often. These findings substantiate the close associations between OHRQoL and other subjective measures of oral health.

The prevalence of oral impacts observed in this study was higher than results reported by other studies in Brazil (80.7\%) and London (40.4\%). ${ }^{16,17}$ The most affected daily performance was eating (75\%), which can be attributed to the ability of child to relate and express it more easily. The aforementioned finding was similar to studies in France and London where eating was prevalent in $43.5 \%$ and $23.2 \%$, respectively. ${ }^{3,17}$ Least affected daily performance was speaking (3.1\%). Other studies found social contact and school work to be least affected daily performances. ${ }^{17,37}$ Perceptions of health and illness may be culturally determined, which combined with 
varied burden of oral diseases may explain such differences in oral impacts in various countries.

The relationship between the clinical indicators and C-OIDP has been previously reported. ${ }^{38}$ The C-OIDP in this study, though not significantly, also varied along the clinical dental status of children. But, this has to be further explored in a larger sample for it to be used in oral health surveys to identify the target group for interventions.

\section{LIMITATIONS}

Despite this, the study had its own limitations, first, a smaller sample size was used in this study. Second, due to regional cultural diversity the tool can only be applicable to Hindi-speaking population.

\section{ConCLUSION}

Children being still in the stage of development of social and psychological skills are sensitive to oral impacts on their QoL. Therefore, a pediatric OHRQoL assessment tool is essential and should be encouraged for assessing the overall impacts of oral health problems. This study established the feasibility of Hindi version of C-OIDP with a satisfactory reliability and validity. Besides allowing for comparisons with other countries, it can be used as a reference for further studies on the OHRQoL in Hindi-speaking children.

\section{ACKnOWLedgment}

We thank Dr Georgios Tsakos (Reader and Honorary Consultant, Dental Public Health Group, Department of Epidemiology and Public Health, UCL, London) for providing the Child OIDP Questionnaire and his constant support and contributions in reviewing the back-translated version of Child OIDP.

\section{References}

1. Park K. Text Book of Preventive and Social Medicine, 23rd ed., Jabalpur, India: Banarsidas Bhanot; 2015.

2. Slade G. Measuring oral health and quality of life. Chapel Hill, NC: Dept. of Dental Ecology, School of Dentistry, University of North Carolina; 1997.

3. Tubert-Jeannin S, Pegon-Machat E, Gremeau-Richard C, et al. Validation of a French version of the child-OIDP index. Eur J Oral Sci 2005;113(5):355-362. DOI: 10.1111/j.1600-0722.2005.00230.x.

4. Cohen L, Jago J. Toward the formulation of sociodental indicators. Int J Health Serv 1976;6(4):681-698. DOI: 10.2190/LE7A-UGBW-J3NR-Q992.

5. Locker D, Grushka M. Prevalence of oral and facial pain and discomfort: preliminary results of a mail survey. Community Dent Oral Epidemiol 1987;15(3):169-172. DOI: 10.1111/j.1600-0528.1987.tb00508.x.

6. Locker D, Allen F. What do measures of 'oral health-related quality of life' measure? Community Dent Oral Epidemiol 2007;35(6):401-411. DOI: 10.1111/j.1600-0528.2007.00418.x.

7. Mashoto KO, Astrøm AN, Skeie MS, et al. Changes in the quality of life of Tanzanian school children after treatment interventions using the child-OIDP. Eur J Oral Sci 2010;118(6):626-634. DOI: 10.1111/j.16000722.2010.00776.x.

8. Bennadi $D$, Reddy C. Oral health related quality of life. J Int Soc Prevent Communit Dent 2013;3(1):1-6. DOI: 10.4103/2231-0762.115700.

9. Do LG, Spencer A. Oral health-related quality of life of children by dental caries and fluorosis experience. J Public Health Dent 2007;67(3):132-139. DOI: 10.1111/j.1752-7325.2007.00036.x.

10. Barbosa TS, Gavião M. Oral health-related quality of life in children: part II. Effects of clinical oral health status. A systematic review. Int J Dental Hygiene 2008;6(2):100-107. DOI: 10.1111/j.16015037.2008.00293.x.
11. Jokovic A, Locker D, Tompson B, et al. Questionnaire for measuring oral health-related quality of life in eight- to 10 -year-old children. Pediatr Dent 2004;26(6):512-518.

12. Filstrup SL, Briskie D, da Fonseca M, et al. Early childhood caries and quality of life: Child and parent perspectives. Pediatr Dent 2003;25(5):431-440.

13. Gherunpong S, Tsakos G, Sheiham A. Developing and evaluating an oral health-related quality of life index for children; The CHILD-OIDP. Community Dent Health 2004;21(2):161-169.

14. Broder HL. Children's oral health-related quality of life questionnaire. Community Dent Oral Epidemiol 2007;35(Suppl 1):5-7. DOI: 10.1111/j.1600-0528.2007.00400.x.

15. Pahel BT, Rozier RG, Slade GD. Parental perceptions of children's oral health: The early childhood oral health impact scale (ECOHIS). Health Qual Life Outcomes 2007;5(1):6. DOI: 10.1186/1477-75255-6.

16. Castro R, Cortes M, Leão A, et al. Child-OIDP index in brazil: Crosscultural adaptation and validation. Health Qual Life Outcomes 2008;6(1):68. DOI: 10.1186/1477-7525-6-68.

17. Yusuf $H$, Gherunpong S, Sheiham A, et al. Validation of an English version of the child-OIDP index, an oral health-related quality of life measure for children. Health Qual Life Outcomes 2006;4(1):38. DOI: 10.1186/1477-7525-4-38.

18. Yusof $Z Y$, Jaafar N. A malay version of the child oral impacts on daily performances (child-OIDP) index: assessing validity and reliability. Health Qual Life Outcomes 2012;10(1):63. DOI: 10.1186/1477-752510-63.

19. Vera C, Moreno X, Rivera D. Adaptation and validation of child oral impact on daily performance index in 11-14-year-old Chilean school children. J Oral Res 2013;2(3):119-124. DOI: 10.17126/joralres.2013. 027.

20. Pentapati KC, Acharya S, Bhat M, et al. Oral health-related quality of life and associated factors in national cadet corps of Udupi district, India. World Journal of Dentistry 2013;4(2):81-85. DOI: 10.5005/ jp-journals-10015-1208.

21. Usha GV, Thippeswamy HM, Nagesh L. . Comparative assessment of validity and reliability of the oral impacts on daily performance (OIDP) frequency scale: A cross-sectional survey among adolescents in Davanagere city, Karnataka, India. Int J Dent Hyg 2013;11(1):28-34. DOI: 10.1111/j.1601-5037.2011.00540.x.

22. Census of India: Abstract of speakers' strength of languages and mother tongues -2001 [Internet]. Censusindia.gov.in. 2016 [cited 3 July 2016]. Available from: http://www.censusindia.gov.in/ Census_Data_2001/Census_Data_Online/Language/Statement1. aspx.

23. Pal D. Quality of life assessment in children: A review of conceptual and methodological issues in multidimensional health status measures. J Epidemiol Community Health 1996;50(4):391-396. DOI: 10.1136/ jech.50.4.391.

24. Krisdapong S, Sheiham A. Which aspects of an oral health-related quality of life measure are mainly associated with global ratings of oral health in children? Community Dent Oral Epidemiol 2014;42(2):129-138. DOI: 10.1111/cdoe.12061.

25. Casas AJ, Ramón Repullo LJ, Pereira CJ. Medidas de calidad de vida relacionada con la salud. Conceptos básicos, construcción y adaptación cultural. Med Clin (Barc) 2001;116(20):789-796.

26. Beaton DE, Bombardier C, Guillemin F, et al. Guidelines for the process of cross-cultural adaptation of self-report measures. Spine 2000;25(24):3186-3191. DOI: 10.1097/00007632-20001215000014.

27. Gjersing L, Caplehorn JR, Clausen T. Cross-cultural adaptation of research instruments: language, setting, time and statistical considerations. BMC Med Res Methodol 2010;10(1):13. DOI: 10.1186/1471-2288-10-13.

28. Bali RK, Mathur VB, Talwar PP, et al. National oral health survey and fluoride mapping 2002-2003 India. New Delhi: Dental Council of India; 2004. 
29. Sischo L, Broder H. Oral health-related quality of life: What, why, how, and future implications. J Dent Res 2011;90(11):1264-1270. DOI: $10.1177 / 0022034511399918$.

30. World Health Organization. Oral Health Survey. Basic Methods., 5th ed., Geneva (France): WHO Press; 2013.

31. Gherunpong S, Tsakos G, Sheiham A. A sociodental approach to assessing dental needs of children: Concept and models. Int J Paediatr Dent 2006;16(2):81-88. DOI: 10.1111/j.1365-263X.2006.00701.x.

32. Shrout PE, Yager TJ. Reliability and validity of screening scales: Effect of reducing scale length. J Clin Epidemiol 1989;42(1):69-78. DOI: 10.1016/0895-4356(89)90027-9.

33. Streiner DL, Norman GR. Health measurement scales. In: A practical guide to their development and use, 2nd ed., New York: Oxford University Press; 2000. pp. 54-68.
34. Ware JE, Brook RH, Davies AR, et al. Choosing measures of health status for individuals in general populations. Am J Public Health 1981;71(6):620-625. DOI: 10.2105/AJPH.71.6.620.

35. Kline P. A handbook of psychological testing 2 nd ed., London: Routledge; 2000.

36. Bibace R, Walsh M. Development of children's concepts of illness. Paediatrics 1980;66(6):912-917.

37. Montero J, Yarte JM, Bravo M, et al. Oral health-related quality of life of a consecutive sample of Spanish dental patients. Med Oral Patol Oral Cir Bucal 2011;16(6):810-815. DOI: 10.4317/medoral. 16790.

38. Montero J, Rosel E, Barrios R, et al. Oral health-related quality of life in 6- to 12-year-old schoolchildren in Spain. Int J Paediatr Dent 2015;26(3):220-230. DOI: 10.1111/ipd.12193. 